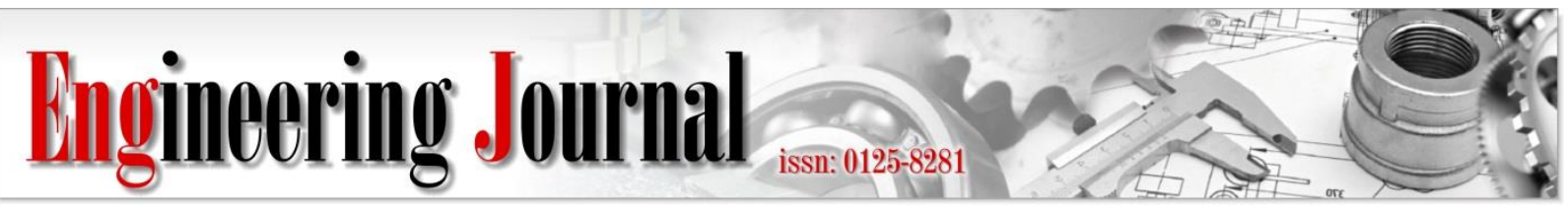

Article

\title{
Towards a Successful Extension of Time (EoT) Claim: A Consensus View of Construction Professionals via a Modified Delphi Method
}

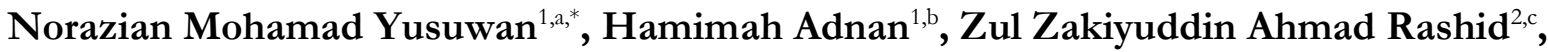 \\ Wan Norizan Wan Ismail ${ }^{1, \mathrm{~d}}$, and Noor Aisyah Asyikin Mahat ${ }^{1, \mathrm{e}}$ \\ 1 Center of Studies for Quantity Surveying, Universiti Teknologi MARA, Malaysia \\ 2 School of Housing, Building and Planning, Universiti Sains Malaysia, Malaysia \\ E-mail: anorazianmy@uitm.edu.my (Corresponding author), bhamimah689@uitm.edu.my,

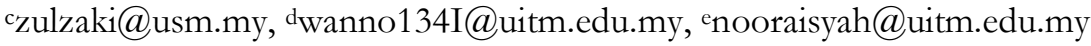

\begin{abstract}
Undeniably, the claim document provides an opportunity for the claimants to defend and fight for their rights. Hence, it should be prepared in a well-organized, professional and convincing manner to facilitate the assessor in assessing the claim. However, it is not an easy task as a good claim not only requires fact and evidences but also demands other important elements that complement each other. Despite the many studies that have been carried out with regard to improving the management of contract claims, yet very little research has been conducted to address the issue in relation to the extension of time (EoT) claim, specifically as to what constitutes a good EoT claim and the possible measures that can be taken by industry players towards the successful settlement of an EoT claim. This paper reports on a Delphi study focusing on identifying the success elements for EoT claim specifically in the Malaysian construction industry. Two rounds of a modified Delphi surveys were conducted and consensus was obtained from twelve experts. The Delphi survey has successfully elicit experts' consensus on the elements that perceived to be the most important element in producing a quality EoT claim that may lead to a speedy, successful and amicable settlement of such claim. Findings from this study is expected to provide an aid in assisting the claimants in the preparation of claims through the identification of the success elements for EoT claims that will then lead towards achieving harmonious claim settlement.
\end{abstract}

Keywords: Extension of Time (EoT), construction industry, modified Delphi, experts, construction delay.

ENGINEERING JOURNAL Volume 25 Issue 1

Received 9 June 2020

Accepted 25 November 2020

Published 31 January 2021

Online at https://engj.org/

DOI:10.4186/ej.2021.25.1.263

This article is based on the presentation at the 4th International Conference on Research Methodology for Built Environment and Engineering 2019 (ICRMBEE 2019) in Bangkok, Thailand, 24th-25th April 2019. 


\section{Introduction}

The construction industry is one that is complex and unique in nature. Its lifecycle involves complex endeavours involving multiple parties undertaking numerous tasks, each with varying levels of interrelated resources[1]. Such a situation exposes the construction industry to a lot of inherent uncertainties and unpredictable circumstances compared to other industries [2-4]. It is difficult to complete a project on schedule in an industry that is plagued by risks and uncertainties, and thus, delays are common and inevitable [5-8]. On-time project completion has always been an indicator of the success of a project. It is a well-known fact that construction time performance is the basis for classifying a project as "successful" or not, along with the cost and quality of the project [9-11]. Furthermore, construction time performance is not only a benchmark for assessing the performance of a project, but is also a sign of the efficient organization of a project $[12,13]$. While successful completion of construction projects is a primary goal for the stakeholders, schedule, budget and other problems often occur, usually through claims and disputes[14], and conflicts are frequently started when claims are submitted [15].

Delays in construction projects may result in various effects and consequences. They often give rise to adversarial relationships between stakeholders, distrust, litigation, arbitration, cash-flow problems and a general feeling of apprehension towards each other [16]. As the delay would lead to the inability to achieve on-time project completion, it may also result in unanticipated extra costs, client dissatisfaction and other consequent problems [17]. On top of that, the most common outcome of a project delay is that it may give rise to a need to apply for an extension of time in order to be given sufficient time to complete the project. Since delays are regarded as the norm in the construction industry, the extension of time (EoT) claim emanating from such delays has been found to be the major source of claims in the construction industry. In fact, [18] viewed claims originating from delays in construction projects as an integral part of the modern construction process.

Claims in relation to time are among the contractual claims that are unavoidable in any construction project. The extension of time claim is often cited as being extremely complex and difficult to resolve, and hence, it can lead to disputes if not properly handled $[6,19,20]$. Provisions for dealing with time extensions are normally established in most standard forms of contracts. Unfortunately, most forms of contracts contain only the general procedures and entitlement for an extension of time, with some under-defined areas that are open to diverse interpretations that would sometimes lead to disputes and disagreements amongst the parties involved [21]. In addition to that, [22] affirmed that although various forms of contracts contain provisions for dealing with time-related issues, they either fail to address the issues adequately or do not consider them at all. This is in line with an earlier statement made by [23] in which he claimed that EoT clauses in construction contracts are not prescriptive and are drafted in a general way, such that they fail to assist the contracting parties in handling time-related claims and issues. As claims cannot be appropriately forecast, its prevention as well as detection endeavours entail a robust claim management [24]. As they further highlighted, claim management pertains to the practices involved to remove or avert more construction claims and react swiftly when a claim occurs. An effective claims management process is therefore essential to ensure that any contractual claims that arise are dealt with in a way that is fair to all parties involved.

\section{The Extension of Time (EoT) Claim}

The entitlement to extension of time is not simply a matter of producing a list of the events that gave rise to the delays in the construction projects; rather, the contractor must demonstrate how the listed events caused delays and how they impacted the critical path, which then altered the overall duration of the project [22]. The claims for extension of time and additional cost are among of the contractual claim that cannot always be granted by the employer, which may consequently cause the employer experiences difficulties in making decisions [25]. The EoT claim can succeed if the contractor can establish causation, liability and damage to each risk event [26]. In view of this, [27] recommended that, to improve the likelihoods of success in claims, contractors must closely adhere to the steps stipulated in the contract, provide a breakdown of the alleged additional time, and present sufficient documents. [28], on the other hand, emphasized that the employer is only bound to meet claims that are based on some express or implied provision of the contract or rule of law, and the onus is on the contractor to substantiate the claim. He went on to add that to ensure that his claim will be entertained, the contractor must be able to demonstrate that he has followed the administrative machinery provided in the contract, whereby failure to do so will usually negate his claim. The easiest way to put forward a claim is by verbal means, but there are ways to make it well documented to comply with administration, which is by submitting written proposal and is equipped by supporting data [25]. In view of the fact that the industry participants generally lack understanding about what claims are, how they arise and how to handle them efficiently, fairly and expeditiously [29], this paper aims to identify the elements that are absolutely essential to be included in the EoT claim to ensure the success of such a claim.

\subsection{Producing a Quality EoT Claim}

Assembling a claim is never an easy task. It should be logically constructed, well-organised and factually convincing to prove that the claimant is innocent while the other party is at fault [30]. [31], on the other hand, emphasised that it is vital to place a great deal of 
attention on the end user of the claim, i.e. the assessor, as it will determine what he/she needs to be told in order to make a decision. He then asserted that in a situation where the claim is directed to the engineer or the architect who has administered the project, it may be safe to conclude that he/she will not need extensive background information regarding the project, while in contrast, if it is meant for the judge or arbitrator, it is highly likely that he/she will need at least some understanding of the project as he/she has had no prior involvement in it.

Undeniably, the claim document provides an opportunity for the claimants to defend and fight for their rights. Therefore, it should tell a story with clear and definite themes that can be readily communicated, understood and remembered [32]. Most importantly, the theme should be the strongest argument in support of the claimant's theory of recovery, duly supported by relevant facts and evidence. In order for the claim to be success or at least to reduce the likelihood of failure and rejection of such a claim, [33] laid out the elements that underlie a successful claim, using the abbreviation CEES; C for Cause; E for Effect; E for Entitlement; and S for Substantiation.

Any claim made should have a cause; the event which has given rise to the claim in which one party to the contract has suffered damages for which it should be compensated by the other party [30, 33]. Another vital part of the EoT claim is the demonstration that the delay events had an effect on the progress of the entire project. However, demonstrating the impact of delays on the schedule of a project is perhaps the most challenging task to be performed, especially when there is more than one delaying event [33-36]. In term of entitlement, it is a golden rule that the time of completion can only be extended if it is permitted by the contract. Therefore, it is vital for the contractor to check for the entitlement to an extension of time as it may vary depending on the type of contract used. Eligibility under the contract is pointless without compliance. To preserve the contractor's right to claim, [33] emphasised that any conditions precedent to entitlement to an extension of time must be fully complied with, or in the case of non-compliance, a justification has to be made as to why the conditions should not affect the contractor's entitlement.

In substantiating the EoT claim, it is inherently dangerous to allow facts or assertions to speak for themselves as the risk is that they will be interpreted in a way which is not intended [31]. Hence, the cause, the effect and the entitlement to an EoT claim not only have to be established and demonstrated, but most importantly, it has to be substantiated. [33] referred to substantiation as "proving to a reasonable level that all statements made, points relied on, calculations submitted and the like are correct". In order to prove or substantiate the claim, it should contain evidence that shall be true, comprehensive and be of the force of law, and that which the lawyer would use in his trial $[33,37]$.
Other than the aforementioned four (4) key elements attributable to a successful EoT claim, a no less important aspect that demands a greater amount of attention by the claimant in preparing the EoT claim is how to put everything in a claim submission or, in other words, the presentation of a claim. Within a prescribed time limit, as stipulated in the contract, the contractor has to prepare and submit a detailed claim that not only contains a narrative explaining what the claim is all about, but is fully supported with particulars to prove and justify what the claim is for. Basically, the presentation of a claim can be made in a variety of ways, and all too often the claimants may prefer to use their own particular form that might be influenced by their own skills, experience and company's format. It is vital for the contractors to present their claim in an appropriate manner, not only to attract the attention of the assessor but most importantly, to make the assessor's job easier and hence, speed up the evaluation process. [38] professed that the quality of a claim report is closely related to the success or failure of such a claim. If it is not well presented, it will often make the contractor lose his favourable position in the claim, and even if everything goes well, the result will be largely discounted and may even fail [38, 39]. Thus, a claim should be written in a format that emphasizes the fact that a contract was breached, and the innocent party must then demonstrate the resulting harm was caused by the owner's action or inaction [30]. Further, [39] postulated that good claim should be persuasive and logically strong. Therefore, compilation skills are needed to produce a good claim that is not only convincing but which is presented in a most appropriate, proper and professional way.

Since a well-presented claim report demonstrates the professionalism, not only of the company presenting it, but also of the individual who compiled it, [33] suggested seven (7) key aspects that need to be emphasized in presenting and documenting a claim, namely: appropriate writing style, making the document user-friendly, making the claim as a standalone document, writing the narrative on the assumption that the reviewer has no previous knowledge of the project, leading the reviewer to a logical conclusion, use of the narrative to explain other documents, and use of exhibits and additional documents as substantiation.

A vital part of a claim document is that it must contain a concise statement of what the claim is all about. [33] asserted that it is very annoying for a reviewer to have to reread the claim report in order to try to make sense of what is written. Therefore, the writing style is crucial to ensure that the message to be delivered (the claim statement) is clear and easily understood by those who read it. Where possible, the narrative should not be expressed in overly argumentative or combative language $[31,32]$. Legalese, infrequently-used words and complicated language that may affect a proper understanding of a narrative should be avoided or, at the very least, be minimised [33]. 
The next important aspect in presenting a claim is it should be a user-friendly document. A claim should be drafted in such a way that it will make the assessor's job as pleasant as possible, such as by using a large font and suitable line spacing with appropriate margins to make it convenient for the assessor to assess the claim. The narrative should be comprehensive and logically organised, especially when it contains references to other documents included as substantiation [32, 33]. In doing so, any documents accompanying the narrative should be properly arranged and labelled, while in the event that a narrative is extremely long, an executive summary should be provided.

As the burden of proof lies on the shoulders of the claimant, the claimant holds the responsibility to substantiate any statement made by appending the relevant supporting documents in his claim report. It has to be noted that sometimes the claim will be assessed by someone who is not familiar with the project or has no access to the project records. In this case, the assessor is totally dependent on the submission made by the claimant. To facilitate the assessment process, a claim should contain everything that the assessor has to refer to in making his decision, or in other words, a document should be made into a standalone document, whereby the assessor will not need to look to other sources for information regarding such a claim. The claimant must also work on the assumption that the assessor has no previous knowledge of the project or the circumstances giving raise the claim. Other than making a claim document as a standalone document, the claimant must also ensure that the document contains all the information so that someone who has no prior knowledge of the project will absolutely understand the whole chronology of events even at the first reading.

Next, a good claim should be able to drive the assessor/reviewer to a logical conclusion by having a beginning, middle and an ending [33]. [40] broke up the presentation of a claim into four (4) logical sequences, namely; the introductory part, the contractual basis part, the comprehensive assessment part, and the auxiliary data part. On the other hand, [39] also had their own main components of a claim, which are: the general part, the contract citation part, the calculation of financial claims and time claims part, and the claim evidence part. The name of the components might be different but the basis is identical. The introductory/general part basically contains the description, history and the basis of the claim; the contractual basis/contract citation part establishes the entitlement of such a claim in reference to the contract; the comprehensive assessment/calculation of financial claims and time claims part basically demonstrates the effect of breaches in terms of the finances and the postponed days, while the auxiliary data/claim evidence part collates all the material evidence that may supplement the statement of claim being made, which includes items such as the progress report, site diaries, weather reports, minutes of meetings, work programmes and many others.
The consistency of the document is another important element that demands a greater amount of attention in the presentation of a claim. According to [33], it is not uncommon for a claim to be prepared by more than one person, whereby one person is responsible for the narrative, while someone else is responsible for demonstrating how the delays affect the project duration. In such circumstances, although both elements are prepared by two individuals, consistency is of the utmost importance. A narrative should be written in such a way that everything is consistent so as to avoid confusion and ambiguity that may hamper the assessment process. After all, in any claim, it is vital that each argument and claim made should be supported by relevant particulars as it is never sufficient to make a statement without any substantiation of its veracity [33].

\section{Research Method; A Modified Delphi Survey}

Since its first application over a half of a century ago, the Delphi technique has gained trust amongst researchers as one of the most powerful techniques in eliciting expert opinions. It has been widely utilised in a diversity of research areas and disciplines such as in information system and technology [41, 42], tourism [43], business and management as well as engineering and construction $[44,45]$. Conventionally, this technique has been designed as a group communication process aimed at achieving consensus on a specific issues from a selected panel of experts $[46,47]$. It involves a systematic technique for obtaining expert consensus on a topic being studied, where the experts are required to participate in a multiple iterations or round of surveys [48]. Feedback received will be analysed, and a new questionnaire will be develop to be distribute to the panel of experts in the next round [49]. Following each round, an anonymous summary of the experts' inputs from the previous round will be provided to the experts. The experts will have the opportunity to compare it with their previous response, whereby they are given the chance to maintain or to revise their response in light of the overall results. If common survey tries to identify "what is", the Delphi technique aims to address "what could" or "should be" [46]. In addition, if survey technique is highly dependence on a sample size, it is not so in the case of Delphi technique [42].

Contrary to other method of data collection, the Delphi technique offers several unique features among which are anonymity, iteration with controlled feedback and statistical group response [49-51]. The Delphi survey is managed in a totally anonymous way where the panel of experts remain unknown to one another [49, 52, 53]. As it maintains the anonymity of the participants, it allows participants to freely express their views without any pressure or influence by the others $[54,55]$. This is the unique characteristic that the Delphi method has in comparison with other method of data collection involving panel of experts such as focus group. The issue 
of autonomy where one could have a power to driven others in focus group is eliminated in a Delphi method due to its anonymous procedure [56]. Another distinct characteristic of a Delphi technique is that it is iterative in nature. It involves multiple iterations or "round" of inquiry where in each round, participant is provided with feedback that involves new information and expresses the group collective opinion $[46,49]$. The iterative nature of this method allows participants to rethink and modify their response with the help of the feedback receive from the rest of the experts $[52,57]$. The questions in a Delphi survey are formulated in such a way that a quantitative and statistical analysis of the answer can be performed [57]. Views from the panel of experts will be statistically analyse and may utilise several approach to report a group response such as the median complemented with minima, maxima, quartiles, and/or the inter-quartile range; or the mean accompanied with standard deviation; or frequency distributions [49].

Classically, the Delphi technique begins with an open-ended questionnaire intends to solicit as many opinions as possible from the expert based on their knowledge, experience and expertise on subject or content area [49, 55, 58]. As the first round aims to identify issues to be addressed in a subsequent round, open-ended type of questions is judged to be the most appropriate as it helps to increase the richness of the data [59]. Over the years since its first introduction, the Delphi technique has gone through a variety of modifications. The techniques has been modified not only to suit with the nature and objectives of the research but also to reach to a specific aims such as to shorten the process and to guarantee the involvement of the participants throughout the rounds [54, 60]. Modified Delphi technique normally does not rely on the expert panel to provide answer in the first round. Rather, the researcher will use other means to collect the answers and presents them to the panel of expert to begin the Delphi process [55]. As Avella [55] further explained, among of the approaches use to collect the initial answer include an extensive review of the relevant literature, a series of interviews with individuals within or outside the study panel, and presents the results of a survey to an external group to the Delphi panel.

\subsection{Designing the Delphi Survey}

Taking into account the context of the study and all the constraints, a modified Delphi technique is suited for this research. The choice was made based on aim of this research; identifying the success elements for EoT claim specifically in the Malaysian construction industry. The two Delphi rounds were conducted to accomplish this aim. To complete the Delphi survey seven stages were involved, started with the selection of experts, followed by the questionnaire development process, first round survey, analysis of first round responses, second round survey, analysis of second round responses and ends with the final report on the Delphi survey.

In order to obtain the most reliable and valuable opinions, the panel of experts for the Delphi survey were carefully selected. The panel of experts consisted of industry professionals identified via semi-structured interviews conducted with the practitioners, i.e. the professional architects and Grade G7 contractors. The interviewees were asked to nominate and recommend other experienced figures within the industry who, in their opinion, have sufficient experience and expertise in dealing with EoT claims. Following the identification of the experts for the Delphi survey through nomination by the other practitioners, the candidates was then being shortlisted based on pre-defined criteria. Among of the criteria devised for a Delphi participant are; practitioners having extensive working experience in the construction industry in Malaysia; practitioners having current, recent or direct involvement in dealing with EoT claims, particularly in private funding projects; and practitioners having sound knowledge and experience with regard to EoT claims. In addition to the expertise required, practitioners should have the willingness and ability to participate during the scheduled Delphi process. Initially, 40 experts were identified and invited via email to participate in the Delphi survey. Of 40 experts contacted, only 17 agreed to participate.

Of the 17 experts who initially agreed to participate, only fifteen 15 responded to the first round. Two (2) experts dropped out due to heavy workload commitments during the survey. From a total of 15 experts participated in Round 1 three (3) were unable to participate in Round 2, left only twelve (12) experts. Round 1 of the modified Delphi survey was the first attempt at rating the importance of each element in influencing the success of the EoT claims. In Round 2, the results of Round 1 were presented, and the experts were asked to review and re-evaluate their responses in the light of the responses from the other experts. Out of twenty-three (23) elements, twenty (20) elements received the consensus of the experts as the elements that will influence the success of EoT claims. Table 1 illustrates the personal profiles of the expert panel in the first round of the Delphi survey. The 15 experts represented a wide distribution of professional figures in the construction industry, with five (5) from the client's organization, six (6) from the consultant's organization, while four (4) were professionals from the contractor's organization. The composition of this group of experts was expected to provide balanced views for the Delphi survey. 
Table 1. Personal Profile of the Delphi Participants.

\begin{tabular}{clccc}
\hline Expert & Current Position & $\begin{array}{c}\text { Level of } \\
\text { Education }\end{array}$ & $\begin{array}{c}\text { Years of Experience in } \\
\text { Construction Industry }\end{array}$ & $\begin{array}{c}\text { Years of Experience } \\
\text { Dealing with EoT Claims }\end{array}$ \\
\hline 1 & Project manager & Master & $16-20$ years & $5-10$ years \\
2 & Director & Master & More than 25 years & $11-15$ years \\
3 & Contract Manager & Master & $21-25$ years & $11-15$ years \\
4 & Contract Manager & Degree & More than 25 years & $21-25$ years \\
5 & Contract Manager & Degree & $21-25$ years & $11-15$ years \\
6 & Contract Manager & Degree & $21-25$ years & $11-15$ years \\
7 & Quantity Surveyor & Degree & $16-20$ years & $11-15$ years \\
8 & Project manager & Degree & $16-20$ years & $11-15$ years \\
9 & Contract Manager & Degree & More than 25 years & $21-25$ years \\
10 & Quantity Surveyor & Master & $11-15$ years & $5-10$ years \\
11 & Project manager & Degree & $21-25$ years & $11-15$ years \\
12 & Contract Manager & Master & $21-25$ years & $11-15$ years \\
13 & Project manager & Degree & More than 25 years & $21-25$ years \\
14 & Quantity Surveyor & Degree & $11-15$ years & $11-15$ years \\
15 & Planning Engineer & Master & $5-10$ years & $5-10$ years \\
\hline
\end{tabular}

\section{Data Analyses and Results}

\subsection{Delphi Round One- Rank \& Weight}

As this was a modified Delphi survey, the Round 1 questionnaire contained questions with pre-selected items for the panellists to indicate their response. This round was for the panellists to assess the importance of each element in determining the success of EoT claims obtained from the views expressed by the interviewees during the semi-structured interviews and from an extensive literature review, which was later confirmed by the professionals during the pilot test of the questionnaire. Following extensive reviews of previous researches and the semi-structured interviews conducted with industry practitioners, a list of 23 items were listed as elements that contribute to a successful EoT claim. Hewitt [33] simplified the essential elements for a successful claim by using the acronym of CEES: C = cause; $\mathrm{E}=$ effect; $\mathrm{E}=$ entitlement; and $\mathrm{S}=$ substantiation. In this research, Hewitt's guideline was adapted and modified, with one new category being included. The categories were cause, effect, entitlement, substantiation and a new category, presentation. The cause-element consisted of two (2) items, while the effect-element consisted of three (3) items. On the other hand, the entitlement-element, substantiation-element and presentation-element consisted of four (4), one (1) and thirteen (13) items, respectively.

\subsection{Delphi Round Two- Re-Evaluating the Ratings}

Upon completion of the first round of the survey, the scores of each item, as rated by the panellists, were then recorded and analysed, in which the frequency, mean and standard deviation of each item were computed and the results were provided to the panellists in the second round of the survey. The items were ranked in descending order based on the mean scores from 5 - 1 (extremely important to not important at all), which indicate the importance of the elements in determining the success of the EoT claim as perceived by the panel of experts. If there is a tie between the mean score, the standard deviation of the items will be used to break the tie. The tied items with the lowest standard deviation scores will be ranked first. As the standard deviation indicates the dispersion of variables around the mean values, a smaller standard deviation indicates more agreement on a particular item $[61,62]$.

Since this was the final round of the Delphi survey, the consensus measurement for this research was established. Although there are a wide variety of ways to measure consensus in previous studies, [63]proposed two alternatives on how consensus can best be measured: (a) if the number of samples $(\mathrm{N}) \geq 35$; standard deviation $<1.00$ (see Seibert [64]), (b) if $\mathrm{N}<35$; consensus is considered to have been achieved on items that received $\geq 80 \%$ of panel agreement on the highest two or three points (see [65-67]. For this research, an agreement criterion of $80 \%$ was established as the minimum level considered for consensus. Those items that attracted below $80 \%$ agreement in the two highest scales of importance, i.e. $4=$ important, $5=$ extremely important, were considered as not important and hence did not require any further consideration. Those items that met the criterion for consensus were concluded to be important as the elements that determine the success of EoT claims. Although there was flexibility on how to establish the percentage of agreement, $80 \%$ was selected for this research in order to have a high level of consensus and to add credibility to the results [65]. 
Finally, after the two rounds of a Delphi survey, out of twenty-three (23) elements, twenty (20) elements received the consensus of the experts as the elements that will influence the success of EoT claims. Two rounds of the modified Delphi survey were considered sufficient for this research due to the following reasons:

a) Standard Deviation: The results from Round 2 showed that the standard deviation for those items that met the experts' consensus were very close indeed to those of the first round (Table 2). As the standard deviation describes the dispersion of variables around the mean value, a closer standard deviation indicates a high degree of concentration around the mean value and hence, shows a high level of agreement between the experts.

b) No additional comments had been added by the experts in Round 1 and Round 2.

Overall, it was felt that a third round of the Delphi survey would not add to the indicators provided by the first two rounds. Thus, the Delphi survey was terminated at Round 2.

Table 2 shows that the standard deviation for both items under cause-elements in round 2 was smaller than in round 1. Both items also tied in terms of its mean score and a standard deviation. For items under effectelements category, there is no change in the rank order of the item except that the respective ranks of "the narrative should contain details of the work affected, estimated affected duration, status of the work at the time the event occurs, and the consequences of the events should be well described to demonstrate the cause and effect" and "in the event of concurrent delay, each delaying event should be analysed individually and collectively" are inter-changed between round 1 and round 2. Item that ranked first in entitlement-category remain the same as in round 1, however, being equal with "the contractor must be able to demonstrate that he has used his best endeavours to mitigate/minimise the delay" which rose from third to first rank. Meanwhile "any condition precedents to entitlement should be examined in the claim and the contractor must be able to demonstrate that he has complied with such provisions (e.g. notice requirement)" are lowered from second to third rank. Item under substantiation-element category shows an increase in the mean value while indicating a smaller standard deviation in round 2 compared to round 1. For items under presentation-elements category, there is no change in the order of their mean ratings except that "make the submission user-friendly" is raised from third to second rank; "write the narrative on the assumption that the assessor has no previous knowledge of the project" is raised from fourth to third rank; "avoid the use of acronyms and abbreviations" is raised from thirteenth to eighth rank (being equal to "avoid the use of legalese and unnecessarily complicated language"); and "present the reference material and documents used as substantiation in a separate volume to the narrative" is raised from twelfth to tenth rank. Other than that, "lead the assessor to a logical conclusion" is lowered from second to third rank. Overall, all items under cause-elements category, effect-elements category, entitlement-elements category, substantiation-element category and presentation-elements category indicating a smaller standard deviation in round 2 compared to round 1 except for a slight increase in the value of standard deviation for item "in the event of concurrent delay, each delaying event should be analysed individually and collectively". As the standard deviation indicates the dispersion of variables around the mean values, a smaller standard deviation indicates more agreement on a particular item $[57,58]$.

\section{Conclusion}

Findings from the Delphi survey with regard to the elements that contribute to the success of EoT claims revealed that the elements of success were closely related to the sufficiency and completeness of the documents to substantiate claims and also the competency of handling claims. Hence, it can be inferred that records and documentation along with the competency of handling claims demand a great deal of attention if a speedy, successful and amicable settlement of EoT claims is to be attained. The chances of success of the EoT claim submitted can be improved if the professionals involved are able to fully grasp what constitutes a good claim. Undeniably, experience is a good teacher, but experience can not only be gained through one's own experience but also by learning from the experiences of others. A willingness to learn is of the utmost importance as knowledge is expanding by the minute. Knowledge can be enhanced through various ways such as by attending seminars, workshops, conferences, and so on, and these are definitely good ways of building competency. Other than that, in order to be competent in managing claims, it is essential for everyone involved to acquire adequate knowledge not only on technical construction but also to acquire a clear understanding of contractual terms and their implications, as these will influence their behaviour towards contract compliances that might influence the way they handle claims and the chances of success.

\section{Acknowledgement}

The authors would like to acknowledge the support of funding from the Ministry of Higher Education of Malaysia under the Fundamental Research Grant Scheme (FRGS) for this research. Special thanks also to the reviewers for their invaluable comments on this paper. Not forgetting that special gratitude is given to those industry practitioners who responded and contributed their valuable input in completing the Delphi survey. 
Table 2. Round 1 and Round 2 Results for Elements for a Successful EoT Claim.

\begin{tabular}{|c|c|c|c|c|c|c|c|}
\hline \multirow{2}{*}{\multicolumn{2}{|c|}{ Item }} & \multicolumn{3}{|c|}{$1^{\text {st }}$ Iteration } & \multicolumn{3}{|c|}{$2^{\text {nd }}$ Iteration } \\
\hline & & $M$ & $S D$ & Rank & $M$ & $S D$ & Rank \\
\hline \multicolumn{8}{|c|}{ Cause-Elements } \\
\hline 1. & $\begin{array}{l}\text { It must be an event or a circumstance that has given } \\
\text { rise to the claim (i.e. late possession of site, force } \\
\text { majeure, exceptionally inclement weather, etc.). }\end{array}$ & 4.47 & 0.833 & 2 & 4.92 & 0.289 & 1 \\
\hline 2. & $\begin{array}{l}\text { Liability for the event. The responsibility for an event } \\
\text { must rest either on the employer, his agents } \\
\text { (consultants), or it is a neutral event, which is beyond } \\
\text { the control of any parties, i.e. force majeure. }\end{array}$ & 4.80 & 0.414 & 1 & 4.92 & 0.289 & 1 \\
\hline \multicolumn{8}{|c|}{ Effect-Elements } \\
\hline 1. & $\begin{array}{l}\text { Establish link between cause and effect (Delay analysis } \\
\text { should demonstrate the effect of the delay event on } \\
\text { the contractor's work programme). }\end{array}$ & 4.60 & 0.507 & 1 & 4.92 & 0.289 & 1 \\
\hline 2. & $\begin{array}{l}\text { The narrative should contain details of the work } \\
\text { affected, estimated affected duration, status of the } \\
\text { work at the time the event occurs, and the } \\
\text { consequences of the events should be well described } \\
\text { to demonstrate the cause and effect. }\end{array}$ & 4.33 & 0.617 & 3 & 4.42 & 0.515 & 2 \\
\hline 3. & $\begin{array}{l}\text { In the event of concurrent delay, each delaying event } \\
\text { should be analysed individually and collectively. }\end{array}$ & 4.47 & 0.516 & 2 & 4.25 & 0.622 & 3 \\
\hline \multicolumn{8}{|c|}{ Entitlement-Elements } \\
\hline 1. & $\begin{array}{l}\text { Entitlement in the contract; identify the contract } \\
\text { provision under which the claim is being made. }\end{array}$ & 4.67 & 0.487 & 1 & 4.92 & 0.289 & 1 \\
\hline 2. & $\begin{array}{l}\text { The contractor must be able to demonstrate that he } \\
\text { has used his best endeavours to mitigate/minimise the } \\
\text { delay. }\end{array}$ & 4.07 & 0.961 & 3 & 4.92 & 0.289 & 1 \\
\hline 3. & $\begin{array}{l}\text { Any condition precedents to entitlement should be } \\
\text { examined in the claim and the contractor must be able } \\
\text { to demonstrate that he has complied with such } \\
\text { provisions (e.g. notice requirement). }\end{array}$ & 4.40 & 0.632 & 2 & 4.67 & 0.492 & 3 \\
\hline \multicolumn{8}{|c|}{ Substantiation-Element } \\
\hline 1. & $\begin{array}{l}\text { Relevant documents of evidence to support the claim } \\
\text { such as correspondence, minutes of meetings, site } \\
\text { diaries, weather reports, photographs, etc. should be } \\
\text { tagged along for the contract administrator's reference } \\
\text { and verification. }\end{array}$ & 4.73 & 0.457 & 1 & 4.92 & 0.289 & 1 \\
\hline \multicolumn{8}{|c|}{ Presentation-Elements } \\
\hline 1. & $\begin{array}{l}\text { The document of claim must be well and } \\
\text { professionally presented to make the assessor's job as } \\
\text { easy and as pleasant as possible. }\end{array}$ & 4.53 & 0.639 & 1 & 4.67 & 0.492 & 1 \\
\hline 2. & $\begin{array}{l}\text { Make the submission user-friendly such as by } \\
\text { providing a clear arrangement and proper labelling to } \\
\text { enable the assessor to locate any references, especially } \\
\text { when the narrative contains references to other } \\
\text { documents of substantiation. }\end{array}$ & 4.40 & 0.736 & 3 & 4.58 & 0.669 & 2 \\
\hline 3. & $\begin{array}{l}\text { Write the narrative on the assumption that the } \\
\text { assessor has no previous knowledge of the project. }\end{array}$ & 4.20 & 0.861 & 4 & 4.42 & 0.515 & 3 \\
\hline 4. & $\begin{array}{l}\text { Lead the assessor to a logical conclusion. The } \\
\text { document of claim must be properly arranged in such } \\
\text { a way that it has a beginning, middle, and end. }\end{array}$ & 4.40 & 0.632 & 2 & 4.42 & 0.515 & 3 \\
\hline 5. & $\begin{array}{l}\text { Make the submission a standalone document by } \\
\text { including everything which the assessor will need to } \\
\text { refer to. }\end{array}$ & 4.00 & 0.925 & 5 & 4.33 & 0.492 & 5 \\
\hline 6. & $\begin{array}{l}\text { Use the narrative to explain other documents attached } \\
\text { as substantiation or in support of the narrative. }\end{array}$ & 3.93 & 0.798 & 6 & 4.17 & 0.718 & 6 \\
\hline
\end{tabular}




\begin{tabular}{|c|c|c|c|c|c|c|c|}
\hline \multirow{2}{*}{\multicolumn{2}{|c|}{ Item }} & \multicolumn{3}{|c|}{$1^{\text {st }}$ Iteration } & \multicolumn{3}{|c|}{$2^{\text {nd }}$ Iteration } \\
\hline & & $\boldsymbol{M}$ & $S D$ & Rank & $\boldsymbol{M}$ & $S D$ & Rank \\
\hline 7. & $\begin{array}{l}\text { Any wording, tittles and the like included in the } \\
\text { supporting documents must be consistent with the } \\
\text { narrative. }\end{array}$ & 3.93 & 0.798 & 6 & 4.17 & 0.718 & 6 \\
\hline 8. & Avoid the use of acronyms and abbreviations. & 3.47 & 0.915 & 13 & 4.00 & 0.603 & 8 \\
\hline 9. & $\begin{array}{l}\text { Avoid the use of legalese and unnecessarily } \\
\text { complicated language. }\end{array}$ & 3.80 & 0.774 & 9 & 4.00 & 0.603 & 8 \\
\hline 10. & Identify quotations correctly and consistently. & 3.80 & 0.861 & 10 & 4.00 & 0.853 & 10 \\
\hline 11. & $\begin{array}{l}\text { Present the reference material and documents used as } \\
\text { substantiation in a separate volume to the narrative. }\end{array}$ & 3.60 & 1.183 & 12 & 4.00 & 0.853 & 10 \\
\hline
\end{tabular}

\section{References}

[1] D.-J. Gibbs, et al., "An investigation into whether building information modelling (BIM) can assist with construction delay claims," in First UK Academic Conference on BIM, 2012, Newcastle Business School \& School of Law Building, Northumbria University.

[2] B. I. N. Ayudhya, "Evaluation of common delay causes of construction projects in Singapore," Journal of Civil Engineering and Architecture, vol. 5, no. 11, pp. 1027-1034, 2011.

[3] A. KarimiAzari, et al., "Risk assessment model selection in construction industry," Expert Systems with Applications, vol. 38, no. 8, pp. 9105-9111, 2011.

[4] N. Tawil, et al., "Determination of the causes of the construction delay in higher learning institutions in Malaysia using the rasch model analysis," Life Science Journal, vol. 11, no. 7, pp. 308-316, 2014.

[5] I. Adhikari, S.-Y. Kim, and Y.-D. Lee, "Selection of appropriate schedule delay analysis method: Analytical Hierarchy Process (AHP), in Technology Management for the Global Future, 2006, PICMET 2006, IEEE.

[6] N. B. Chaphalkar and K. Iyer, "Factors influencing decisions on delay claims in construction contracts for Indian scenario," Australasian Journal of Construction Economics and Building, vol. 14, no. 1, pp. 32-44, 2014.

[7] M. Jamil, N. A. Mufti, and W. S. Dar, "Analysis of time slippage for construction projects in public sector: Owner's perspective," Mebran University Research Journal of Engineering \& Technology, vol. 31, no. 4, pp. 559-570, 2012

[8] H. Nazarpour, M. J. T. Amiri, and M. Hemmatian, "Prioritizing delay causes in construction projects in Mazandaran province (Iran) and presenting solutions for improving it," Applied mathematics in Engineering, Management and Technology, vol. 2, no. 4, pp. 242-251, 2014.

[9] S. M. Hafez and H. M. Elsaka, "Identifying potential delay situations in advance to define construction contract obligations of public buildings," International Journal of Education and Research, vol. 1, no 9, pp. 1-8, 2013.
[10] L. Le-Hoai and Y. Dai Lee, "Time-cost relationships of building construction project in Korea," Facilities, vol. 27, no. 13-14, pp. 549-559, 2009.

[11] S. R. M. Riazi, "The use of supply chain management to reduce delays as result of preconstruction deficiencies in Malaysian public sector construction projects," Civil Engineering and Built Environment, Faculty of Science and Engineering, Queensland University of Technology, Australia, 2014.

[12] S. A. Assaf and S. Al-Hejji, "Causes of delay in large construction projects," International Journal of Project Management, vol. 24, no. 4, pp. 349-357, 2006.

[13] D. R. Ogunsemi and G. O. Jagboro, "Time-cost model for building projects in Nigeria," Construction Management and Economics, vol. 24, no. 3, pp. 253258, 2006.

[14] A. Alzeraa, E. E. Kazan, and M. A. Usmen, "Impact of project communications effectiveness on construction disputes," in 6th Annual International Conference on Architecture and Civil Engineering (ACE 2018), 2018.

[15] S. Hansen and S. F. Rostiyanti, "Indonesian contractor professionals' perception on problems in construction claim management," Malaysian Construction Research Journal, vol. 27, no. 1, 2019.

[16] S. M. Ahmed, et al., "Delays in construction: A brief study of the Florida construction industry," in ASC Proceedings of the 39th Annual Conference, 2003.

[17] B.-G. Hwang, X. Zhao, and S. Y. Ng, "Identifying the critical factors affecting schedule performance of public housing projects," Habitat International, vol. 38, pp. 214-221, 2013.

[18] J. K. Yates and A. Epstein, "Avoiding and minimizing construction delay claim disputes in relational contracting," Journal of Professional Issues in Engineering Education and Practice, vol. 132, no. 2, pp. 168-179, 2006.

[19] N. Braimah and I. Ndekugri, "Consultant's perceptions on construction delay analysis methodologies," Joumal of Construction Engineering and Management, vol. 135, no. 12, pp. 1279-1288, 2009.

[20] Y. Kim, K. Kim, and D. Shin, "Delay analysis method using delay section," Journal of Construction 
Engineering and Management, vol. 131, no. 11, pp. 1155-1164, 2005.

[21] E. Palaneswaran and M. M. Kumaraswamy, "An integrated decision support system for dealing with time extensions entittlements," Automation in Construction, vol. 17, no. 4, pp. 425-438, 2008.

[22] H.-Y. Chong, and Y.-W. Leong, "Legal approach on assessment of contractors entittlement to extension of time," African Journal of Business Management, vol. 6, no. 14, pp. 4815-4823, 2012.

[23] T. Farrow, "Developments in the analysis of extensions of time," Journal of Professional Issues in Engineering Education and Practice, vol. 133, no. 3, pp. 218-228, 2007.

[24] K. Hayati, Y. Latief, and A. D. Rarasati, "Causes and problem identification in construction claim management," IOP Conference Series: Materials Science and Engineering, vol. 469, no. 1, p. 012082, 2019.

[25] A. Rachmatullah and S. Hardjomuljadi, "Analysis of accepted claims for extension of time and additional cost in water building projects in Banten Province," International Journal of Scientific Research and Engineering Development, vol. 3, no. 3, 2020.

[26] K. A. A. Alnaas, A. H. H. Khalil, and G. E. Nassar, "Guideline for preparing comprehensive extension of time (EoT) claim," HBRC Journal, vol. 10, no. 3, pp. 308-316, 2014.

[27] M. A. U. Abdul-Malak, M. M. El-Saadi, and M. G. Abou-Zeid, "Process model for administrating construction claims," Journal of Management in Engineering, vol. 18, no. 2, pp. 84-94, 2002.

[28] D. Chappell, Building Contract Claims, 5th ed. John Wiley \& Sons, 2011.

[29] G. Sibanyama, M. Muya, and C. Kaliba, "An overview of construction claims: A case study of the Zambian construction industry," International Journal of Construction Management, vol. 12, no. 1, pp. 65-81. 2012.

[30] G. Kululanga, et al., "Construction contractors' claim process framework," Journal of Construction Engineering and Management, vol. 127, no. 4, pp. 309314, 2001.

[31] N. J. Carnell, Causation and Delay in Construction Disputes, 2nd ed. Blackwell Publishing, 2005.

[32] R. B. Ansley, T. J. Kelleher, and A. D. Lehman, Common Sense Construction Law: A Practical Guide for the Construction Professional, 2nd ed. R. B. Ansley, T. J. Kelleher, and A. D. Lehman, Eds. USA: John Wiley \& Sons, 2001.

[33] A. Hewitt, Construction Claims \& Responses: Effective Writing \& Presentation. Wiley-Blackwell, 2011.

[34] D. Arditi and T. Pattanakitchamroon, "Selecting a delay analysis method in resolving construction claims," International Journal of Project Management, vol. 24, no. 2, pp. 144-155, 2006.

[35] Entrusty Group, "Is the contractor still entittled to extension of time when there is concurrent delay?," in Master Builders. Malaysia, 2006, pp. 101-103.
[36] I. Ndekugri, N. Braimah, and R. Gameson, "Delay analysis within construction contracting organisations," Journal of Construction Engineering and Management, vol. 134, no. 9, pp. 692-700. 2008.

[37] C. B. Chen and D. C. Wang, "Study on the construction process control claims management," Applied Mechanics and Materials, vol. 120, pp. 385388, 2012.

[38] L. Liu, "Study on the present condition of construction claim and countermeasure," in 2010 International Conference on Construction and Project Management (ICCPM 2010), Chengdu, China.

[39] S. Yang and J. Xu, "Construction claims management of civil engineering," Advanced Materials Research, vol. 243, pp. 6348-6351, 2011.

[40] A. S. Oyegoke, "Building competence to manage contractual claims in international construction environment: The case of Finnish contractors," Engineering Construction and Architectural Management, vol. 13, no. 1, pp. 96-113, 2006.

[41] R. El-Gazzar, E. Hustad, and D. H. Olsen, "Understanding cloud computingadoption issues: A Delphi study approach," The Journal of System and Software, vol. 118, pp. 64-84, 2016.

[42] R. Skinner, et al., "The Delphi method research strategy in studies of information systems," Communications of the Association for Information Systems, vol. 37, pp. 31-63, 2015.

[43] H. Konu, "Developing nature-based tourism products with customers by utilising the Delphi method," Tourism Management Perspectives, vol. 14, pp. 42-54, 2015.

[44] N. Tymvios and J. A. Gambatese, "Direction for generating interest for design for construction worker safety-A Delphi study," Journal of Construction Engineering and Management, vol. 142, no. 8, 2016.

[45] A. J. Perrenoud, "Delphi approach to identifying best practices for succession planning within construction firms," International Journal of Construction Education and Research, vol. 16, no. 3, pp. 197-210, 2020.

[46] C.-C. Hsu and B. A. Sanford, "Delpi technique," in Encyclopedia of Research Design, N. J. Salkind, Ed. SAGE Publications, 2012.

[47] A. P. C. Chan, et al., "Application of Delphi method in selection of procurement systems for construction projects," Construction Management and Economics, vol. 19, no. 7, pp. 699-718, 2001.

[48] C. C. Hsu and B. A. Sandford, "The Delphi technique: Making sense of consensus," Practical Assessment, Research \& Evaluation, vol. 12, no. 10, pp. 1-8, 2007.

[49] A. Sourani and M. Sohail, "The Delphi method: Review and use in construction management research," International Journal of Construction Education and Research, vol. 11, no. 1, pp. 54-76. 2015. 
[50] N. C. Dalkey, "The Delphi method: An experimental study of group opinion," RAND Corporation, California, 1969.

[51] M. Awad, et al., "Consensus views on the optimum training curriculum for advanced minimally invasive surgery: A delphi study," International Journal of Surgery, vol. 53, pp. 137-142. 2018.

[52] O. Manoliadis, I. Tsolas, and A. Nakao, "Sustainable construction and drivers of change in Greece: A Delphi study," Construction Management \& Economics, vol. 24, pp. 113-120, 2006.

[53] I.R. Diamond, et al., "Defining consensus: A systematic review recommends methodologic criteria for reporting of Delphi studies," Journal of Clinical Epidemology, vol. 67, pp. 401-409, 2014.

[54] G. J. Skulmoski, F. T. Hartman, and J. Krahn, "The Delphi method for graduate research," Journal of Information Technology Education, vol. 6, no. 1, pp. 121, 2007.

[55] J. R. Avella, "Delphi panels: Research design, procedures. Advantages and Challenges," International Journal of Doctoral Studies, vol. 11, pp. 305-321, 2016.

[56] S. Sahari, et al., "A review of Delphi technique in developing human capital disclosure index," Academy of Accounting and Financial Studies Journal, vol. 22, no. 4, pp. 1-9, 2018.

[57] J. Landeta and J. Barrutia, "People consultation to construct the future: A Delphi application," International Journal of Forecasting, vol. 27, pp. 134-151, 2011.

[58] R. L. Custer, J. A. Scarcella, and B. R. Stewart, "The modified Delphi technique-A rotational modification," Journal of Vocational and Technical Education, vol. 15, no. 2, pp. 50-58, 1999.

[59] C. Powell, "The Delphi technique: Myths and realities," Journal of Advanced Nursing, vol. 41, no. 4, pp. 7, 2003.

[60] S. E. Biggs, et al., "Safety leaders' perceptions of safety culture in large Australasian construction organisation," Safety Science, vol. 52, pp. 3-12, 2013.
[61] B. W. DeLany, "Entry-level job skills needed by wildlife management professionals," doctoral dissertation, The School of Human Resource Education and Workforce Development, Louisiana State University and Agricultural and Mechanical College, 2004.

[62] F. E. Hurme, "Competencies for rural nursing practice," doctoral dissertation, The School of Human Resource Education and Workforce Development, Louisiana State University and Agricultural and Mechanical College, 2007.

[63] M. M. Derus, "Penunjuk kompetensi yang dianggap kritikal untuk pengurus projek dalam Jabatan Kerja Raya," Quantity Surveying Department, Universiti Sains Malaysia, Pulau Pinang, Malaysia, 2012.

[64] M. J. Seibert, "The identification of strategic management counseling competencies essential for the small bussiness and technology development center: A modified delphi strategy," doctoral dissertation, Adult and Community College Education Training and Development Program, North Carolina State University, 2004.

[65] C. K. Thomas, "The role of the public school superintendent in local economic development," doctoral dissertation, Educational Leadership and Policy Studies, Virginia Polytechnic Institute and State University, Virginia, 2002.

[66] D. R. Mirra, "The role of the school superintendent as a technology leader: A Delphi study," doctoral dissertation, Educational Leadership and Policy Studies, Virginia Polytechnic Institute and State University, Virginia, 2004.

[67] J. W. Davidson, "The necessary components of a staff development program to prepare teachers to teach secondary online classes: A Delphi study," doctoral dissertation, Educational Leadership and Policy Studies, Virginia Polytechnic Institute and State University, Virginia, 2005. 


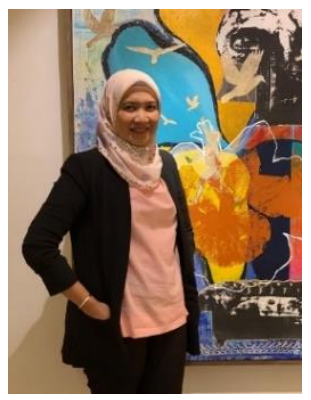

Norazian Mohamad Yusuwan was born in Perak, Malaysia in 1980. She received the BSc in Quantity Surveying, from Universiti Teknologi MARA in 2003 and MSc in Integrated Construction and Project Management in 2007 also from the same university. She received her $\mathrm{PhD}$ in the Specialism of the Built Environment from Universiti Teknologi MARA in 2016.

She is currently a Senior Lecturer in the Centre of Studies for Quantity Surveying, Faculty of Architecture, Planning and Surveying at Universiti Teknologi MARA, Shah Alam, Malaysia. She has four (4) years of working experience as a Contract Executive at a construction and consultant organisation. She has published and presented at international conferences and journals with her main interest in construction and project management, contract and procurement, safety and health in construction, and risk management.

Dr. Norazian Mohamad Yusuwan is a professional member of the Board of Quantity Surveyors Malaysia (BQSM) and a member of the Royal Institution of Surveyors Malaysia (RISM).

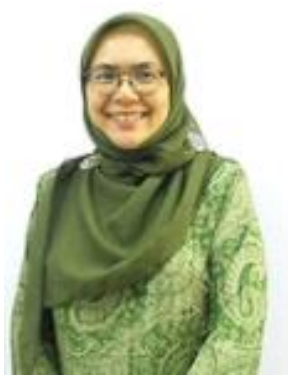

Hamimah Adnan was born in Johor Bahru, Johor, Malaysia in 1963. She received the Bsc in Quantity Surveying, Glasgow Polyechnic, UK (1992), MSc in Construction Management (Risk) from Glasgow Caledonian University, UK. (1994). She received her PhD in Project Management in 2004 focusing on Joint Venture Projects in Malaysia: Factors Critical to Success and later her Post Doctorate study with the Nottingham Trent University, UK (2010).

She is currently the Deputy Dean, Research and Industry Linakges, Faculty of Architecture, Planning \& Surveying, Universiti Teknologi MARA (UiTM) Shah Alam. She is the registered Quantity Surveyor and members of Royal Institution of Surveyors Malaysia (RISM), Chartered Institute of Building (CIOB)and Royal Institution of Surveyors (RICS) UK. Her area of research interest is not limited to the Built Environment (project management, construction economics, facilities management, risk management, contract and procurement but also on strategic alliances, safe cities and green projects. As a result of her active research involvement in her area of interests, she successfully edited and co-authored a total of 11 books, more than 100 papers and presented numerous papers local and international within stated areas of construction management as a result of her active research involvement in her area of interests.

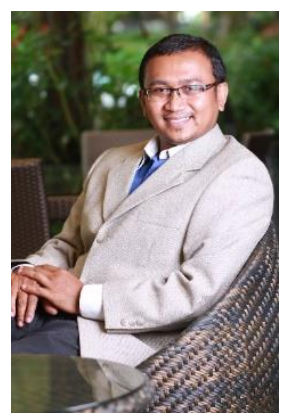

Zul Zakiyuddin Ahmad Rashid is a Senior Lecturer in Construction Management Department, School of Housing, Building and Planning at Universiti Sains Malaysia. He holds a PhD in the Specialism of the Built Environment from Universiti Teknologi MARA, Malaysia. He has published and presented at international conferences and journals with his main interest in construction and project management, construction law and risk management. He also actively involved in various research works related to construction law.

Dr. Zul Zakiyuddin Ahmad Rashid incepted and chaired the Construction Industry Law Centre (CILC), sanctioned by Malaysian judiciary, and various stakeholders of the industry including Malaysian Construction Industry Development Board (CIDB) and related associations.

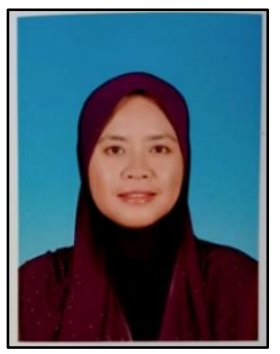

Wan Norizan Wan Ismail is a Senior Lecturer in the Centre of Studies for Quantity Surveying, Department of Built Environment Studies and Technology, Universiti Teknologi MARA, Perak. She obtained Bachelor of Quantity Surveying (Hons.) from Universiti Teknologi MARA, and Master of Philosophy (MPhil) in Construction from Massey University, Wellington, New Zealand. Currently, she is pursuing her $\mathrm{PhD}$ in construction contract and procurement at Universiti Teknologi MARA, Perak. Her research interest includes construction project management, contract and procurement and contractual behavior.

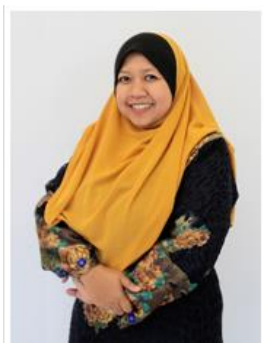

Noor Aisyah Asyikin Mahat is a Senior Lecturer in the Centre of Studies for Quantity Surveying, Faculty of Architecture, Planning and Surveying at Universiti Teknologi MARA, Shah Alam, Malaysia. She earned Bsc. In Quantity Surveying and hold MSc in Construction Contract Management from Universiti of Technologi Malaysia. She is currently pursuing Ph.D in the Specialism of the Built Environment at Universiti Teknologi MARA. Her research interests include construction and project management, Green Construction, and construction economics. 